\title{
NEW LITERACY NEW AUDIENCES: SOCIAL MEDIA AND CULTURAL INSTITUTIONS
}

Angelina Russo and Jerry Watkins

Faculty of Design

Swinburne University of Technology

144 High Street

Prahran

Victoria 3181

Australia

arusso@swin.edu.au,jwatkins@swin.edu.au

http://nlablog.wordpress.com

\begin{abstract}
This paper reports on a major Australian research project which examines whether the evolution in digital content creation and social media can create a new audience of active cultural participants. The project draws together experts from major Australian museums, libraries and screen centres to examine the evolution in digital contentcreation and social media. It explores whether organizations can become active in content generation ('new literacy'), and thereby be linked into new modes of distribution, calling into being 'new audiences'. The paper presents interim findings of the project, describing the theories and methodologies developed to investigate the rise of social media and, more broadly, digital content creation, within cultural institutions.
\end{abstract}

\section{INTRODUCTION}

New Literacy New Audiences is a major 3-year, Australian Research Council funded project which brings together an expert group of strategists and technologists from some of Australia's major cultural institutions to examine how the evolution in digital literacy and content creation can create a new audience of active cultural participants. Theproject aims to deliver:

- a comprehensive survey of the sites where new literacy (e.g. digital storytelling) are emerging in Australia and internationally (to identify best practice); - an examination of narrative and design innovation in relation to these;

- new models of engaging audiences for this innovation - e.g. multiplatform publishing with a focus on tri-platform content;

- a model of consumer-led production for multi-platform publishing, so that professional media and cultural institutions can make the most of emerging sources of creative content, and

- integrated modes of communication for creative as well as instrumental purposes.

The project arose from the recognition that the creation and communication of meaning is radically contextual, requiring attention to production (including ownership and control), institution (including technology), content (text, commodity), audience (consumer) and socio-historical environment (including regulation and standards). The 
project afforded a practical opportunity to explore and delineate how the forces and relations of meaning-creation along this value chain are changing. Additionally, the project aimed to produce practical innovations along this value chain that would be of strategic benefit to end-users.

\section{THEORETICAL CHALLENGES}

The development of media and their impact on society have challenged cultural organizations such as museums, libraries, galleries and universities. New media technologies allow the convergence of rich content, multi-modal communication delivery systems and the development of new spatial (interactive and immersive cultural experiences) and textual (digital storytelling) experiences. Emerging from this convergence of site and screen is the opportunity to consider both the textual and spatial dilemmas of digital cultural communication and propose methods of co-creation for multi-site distribution. By describing the characteristics of interactive cultural experiences and digital storytelling in relation to new forms of cultural participation, this project aimed to establish materials for end-user organisations to consider where, how and to what end new media technologies could augment and/or enhance their visitor experience.

Changes in the notion of consumption, away from behavioural analysis and towards a model of consumption as active, creative work, provide the basis for developing production process and adding value to innovation systems $[1,2,3,4]$ The wave of nonprofessional content (unpaid but not 'amateur' in the old-fashioned, pejorative sense) that has emerged from new media technologies has recently become the focus of economic and legal innovation theory [5,6]. However, semi-professional, 'prosumer', 'pro-am' or domestic content creation is not always effectively structured, presented and disseminated.

New Literacy New Audiences seeks to reconfigure relations between systems and users through institutions and cultural networks, researching and modelling their progression into environments for learning, creative production and distribution. The industry partners identified a need to move beyond information archiving and display and into content generation and more porous community interface. Examining the possibilities and limitations for digital co-creation within these established, culturally rich environments will ultimately inform a model for effective low-cost digital content that will develop out of consumer-led creativity across public, community and commercial sites for a hybrid but national network for Australian content. This can be described as a second generation of new-media content.

Participatory new media are yet to progress into elaborated, organized systems for expression. In the print media, full literacy has historically involved more than the ability to read and write; it also requires engagement with elaborated textual systems like literature or journalism in which individuals may aspire to authorship as well as readership. Investigation is required into how new media may develop an elaborate literate system within their broader ecology. For this to occur, new media development must be seen as not just the tuition of the individual, but also the development of new narrative forms and effective multiplatform publishing across hybrid sites and practices. Thus digital storytelling combines production by non-professionals, usually recruited 
from local communities, with methods and expertise from the professional sphere. It represents a 'missing middle' occupying a gap between community and popular media that was never adequately bridged during the broadcast era. The industry partners in this project unite audiences with an archive of histories, objects and information that can be utilised in content creation. With narrative formats such as digital storytelling and practical techniques for skills dissemination, the project examined how personal experience and community expression could be scaled up to integrate communication (citizenship) and entertainment (audiences).

\section{New Literacy}

For the purpose of this project, new literacy was defined as the skills required to use digital technologies to engage in both cultural consumption and production. Literacy has historically been a field of study most notably discussed in education, but media and cultural studies have recently focused on the "new literacies" and what skills are demanded of audiences as they negotiate the potential of expanding digital services. For example, Nixon proposes that forces such as the global cultural economy and public policies regarding ICTs are now so deeply embedded in our daily lives - at home, work and school - that in many places they are shaping a 'new landscape of communication' and 'new learning environments' [7]. Leu et al suggest that "The new literacies of the Internet and other ICTs include the skills, strategies, and dispositions necessary to successfully use and adapt to the rapidly changing information and communication technologies and contexts that continuously emerge in our world and influence all areas of our personal and professional lives." [8].

The new literacies are a readily recognizable phenomenon: the enormous impact of technology on cultural communication and the resulting systemic shifts should be wellknown to anyone familiar with the printing press, radio, telephone and television. Livingstone [9] describes "media literacy" and examines how its traditional focus on print and audiovisual media has been extended to encompass the internet and other new media. Media literacy is defined as the ability to access, analyze, evaluate and create messages across a variety of contexts:

- Access rests on a dynamic and social process, not a one-off act of provision.

- Analytic competencies include an understanding of the agency, categories, technologies, languages, representations and audiences for media.

- Evaluation - aesthetic, political, ideological and/or economic [all of which are contested].

- Content creation - the internet offers hitherto possibilities for audience content production.

Rather than comment upon the social processes and agencies to which Livingstone refers, this research focused on methods for creating active cultural participation through new literacy.

New Audiences 
Schuler [10] argues that communities are distinguished by lively interaction and engagement on issues of mutual concern and that their well-being contributes to the well being of the state as a whole. ICT can play a role in rebuilding community life by improving communication, economic opportunity, civic participation and education. His position extends to community-oriented electronic communication where community etworks have a local focus.

Schuler fails to provide a credible economic blueprint of how to deliver universal online access for communities, although he does make a case for how institutions can provide greater community access to ICT by providing no-/low-cost public access points. But the relationship between institution and community has far greater potential than the one-way provision of access and facilities. The newly literate community not only has the tools to consume digital culture, it can also work with the institution to create its own digital cultural artefacts.

When communities and institutions co-create digital artefacts to preserve cultural identity, both contribute to the sharing of cultural knowledge and distribution of this knowledge to a wider audience. The co-creation equation is simple: cultural institutions have technical infrastructure and display mechanisms, and communities have original content in the form of narratives. The BBC's Capture Wales[11] provides an excellent example of community co-creation: the institution [in this case, the British Broadcasting Corporation] sponsored a travelling multimedia facility to visit communities and hold workshops in both image manipulation and narrative techniques. This new literacy training has powerful cultural outcomes: the community is empowered to create its own "digital stories", short multimedia narratives constructed from personal photographs and memories. A collection of digital stories can provide a compelling snapshot of a community's cultural identity - the stories are supported by the institution, but created by the community itself.

\section{RESEARCH APPROACH}

Working from an initial period of analysis of worldwide digital storytelling and consumer/user-led innovation using multiplatform interactive media technologies, theproject narrowed to a series of applications suitable to the site-specific purposes of the industry partners. These were framed around the following:

\section{Content networking}

The research utilised existing institutions, enhancing their capacity within the cultural domain and reforming their relationships with audiences. It investigated the potential to provide a model for content creation that would be dispersed and local in origin, building upon exhibition, learning and consumption practices across the community, public and commercial spheres.

\section{Digital Cultural Communication}

The project situated new literacy and new audiences within a continuum of digital cultural communication where experience (immersive and site-specific) and narrative (distributive, generic) could be brought together to create innovative models for multi- 
sourced, multi-site communication and learning. Digital Cultural Communication was defined as new field of research and design which seeks to build a co-creative relationship between the cultural institution and the community by using new media to produce audience-focused cultural interactive experiences.

\section{Co-creative practices}

The project offered solutions for low-cost content creation which utilised the significant cultural collections within museums, galleries and libraries. It built upon international initiatives in consumer co-creation by utilising the spaces, audiences and technical capacity that exists within these organisations.

In order to achieve the project aims, the research team employed a number of approaches to data collection, analysis and dissemination, including:

- Partner Organisation Interviews

- Surveys

- Workshops

The following section details some of the findings from these approaches.

\section{Partner Organisation Interviews}

The National Museum of Australia opened in 2001. It included a Broadcast Studio which could deliver broad technological capabilities and provide applications to connect across Museum spaces and external agencies. The Broadcast Studio was conceived without a strong strategic plan and continues to present challenges for developing programs and events. The Studio offered a case-study for immersive cultural experiences which included broadcast, website and on-site exhibits. In 2006, the researchers interviewed eighteen staff members from the National Museum to ascertain perceptions of the Broadcast Studio; the potential for the Studio to deliver three-way communication programs; and the value of the Studio in relation to existing and future programs. These interviews would then frame the development of a strategy for multi-platform distribution of cultural content.

\section{Perceptions of Studio}

Respondents suggested that The Broadcast Studio had the potential to :

- act as mechanism for integrating arts and technology

- be used to connect broadcast and analogue events within the museum, thus creating greater visibility for programs

- harness the existing community relationships to extend museum content further into regional and remote areas.

- promote materials throughout other institutions

Respondents felt that in order to better utilise the studio, connections between its programming and collections would require professional facilitation. Additionally, curators would require digital literacy training. 


\section{Three-way communication}

This was defined as communication between audiences and institutional programs and collection materials. When asked how the studio could enable meaningful relationships between audiences and collections, respondents suggested that Studio programming could be:

- fostered to create conceptual and creative structures as well as physical structures that encourage and facilitate engagement between audiences and

- facilitate connections between different groups of audiences

Respondents suggested that the Studio could facilitate the multiplicity of discussions and interpretative conversations around what is in the galleries and in the collection. The interviews underpinned the development of an audience/content multiplatform framework which identified the types of content available for display, the platforms which could be used; distribution types and the key audiences who would be targeted for specific types of dissemination. The development of the framework included the recognition that while internal digitization initiatives would drive the majority of programs, there were significant digital artefacts, including audio and visual materials which could be repurposed for further distribution.

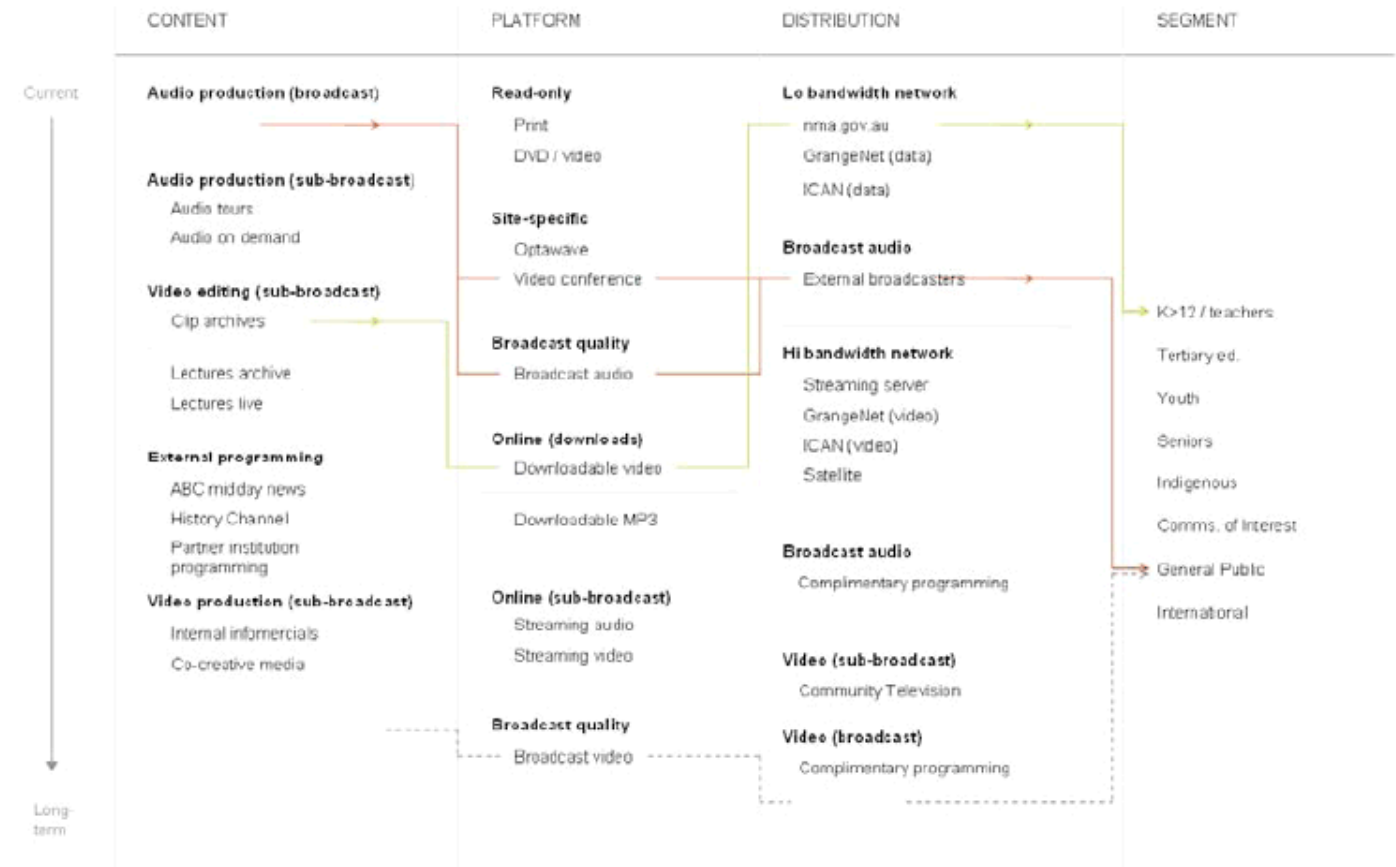

Figure 1 Audience/Content Multiplatform Framework 
Following on from this, a bespoke design system, (multi-platform communicationdesign) was created to enable community members to learn the skills necessary to create digital content. The methodology included a "purpose-built" training program which could deliver the skills necessary for organisations to facilitate the creation of new content. [12]

\section{Surveys}

As the project progressed, the rise of social media necessitated a greater exploration of the ways in which audiences participated with content online. In October 2006, the Forrester Group surveyed 4,556 US youth and 4,475 US adults in December 2006 to learn about their social computing technology use. [13] As a result users were grouped into six different categories of participation as follows:

- $52 \%$ were inactive

- $33 \%$ were spectators (read blogs, watch peer-generated videos and listen to podcasts)

- $19 \%$ were joiners (use social networking sites)

- $15 \%$ were collectors (tag web pages)

- $19 \%$ were critics (comment on blogs, post ratings and reviews)

- $13 \%$ were creators (publish web pages, publish or maintain a blog, upload video to sites like YouTube).

An on-line survey of 2,006 participants across eastern Australia was undertaken in November 2007 using a similar set of questions from the Forrester study in order to make some comparisons. [14] Respondents were asked about the kinds of on-line activities they had undertaken in the previous month, as well as where they accessed the internet, how comfortable they felt with technology and demographic information. The Forrester report provided useful data and classification tools to determine the ways in which audiences participate in on-line activities. Yet, it did little to extrapolate these findings in relation to cultural participation beyond broad genres of interactivity. The Australian data suggested that people who were actively engaged in physical museum visitation tended to be involved in on-line museum activities in greater numbers than those who didn't. Using the Forrester categories to survey the 18-30 year olds resulted in a range of options regarding cultural engagement with visitors both physically and online.

It was here that the opportunities to create networks of participation through social media could be usefully explored. Recent research by Russo et al [15] demonstrated how social media facilitate knowledge exchange by taking advantage of 'network effects' and creating a new forum through which diverse audiences could participate with museums to explore issues and voice these reflections on-line.

\section{Digital Literacy Workshops}

In collaboration with industry partners, the researchers developed two distinct workshops which supported the research findings regarding new literacy and new audiences. 


\section{Co-creative Workshops}

The Australian Museum is exploring co-creation as a result of a 33AUDmillion state grant to fund a new extension, refurbish existing listed structures, and create two major new exhibitions. In order to inform the investment of this grant, the Museum's Audience Research Centre has made significant efforts to listen and respond to the voice of visitors and associated communities in the design of the new exhibitions [16].

Established in 1827, the Museum specialises in natural history and indigenous studies and is the oldest institution of its kind in Australia [17]. This heritage has resulted in a collection of 14.5 million specimens which in turn attract a monthly web visitation rate which regularly exceeds 1.5 million. Since the quantity of web visitors more than satisfies the Museum's public service criteria, management focus is being placed instead on the quality of online experience offered, especially to youth / informal learning communities.

The research team, in collaboration with The Australian Museum explored the organizational ramifications of digital literacy through a series of internal co-creative workshops. Based on the digital storytelling format, the workshops trained staff in script writing, creative production and editing in order to produce microdocumentaries which illustrated some previously unseen facet of the Museum's collections: in effect, bringing informal narrative and the 'human face' into museum communication.

Although off-the-shelf creative applications were a feature of the workshop (principally the use of Sony's Vegas video editing suite) the focus was firmly on team based digital content creation techniques. A three-person team of writer, producer and editor was responsible for producing an original microdocumentary. Through a focus on teamwork rather than technology, this creative digital literacy training was extremely well received by previously techno-resistant participants, proving that "Learning to create content helps one to analyze that produced professionally by others; skills in analysis and evaluation open the doors to new uses of the Internet" [18].

The medium-term destinations for the microdocumentaries are the Museum's labyrinthine website and its new physical exhibitions. The operational strategy was conceived to develop a core of digitally literate staff that would then collaborate with communities of interest already associated with the Museum to establish a sustainable program of co-creative communication using social media.

\section{Planning for Social Media workshop}

This workshop contextualized the use of social media in cultural organizations. It was based on shifts from one-way to three-way communication and was originally structured around: participation; content sharing, incentive and acknowledgement. Over an 18 month period, the workshop developed to articulate these areas more succinctly in relation to changing practices. This led to redefining the strategies for social media use around: engagement, experience, environment and evaluation.

\section{Engagement}

There are a number of ways in which museum audiences engage with issues and events which they experience in the museum. Social media are already being used to discuss organizations and share knowledge outside of the museum. Sites such as 
http://technorati.com/ and http://au.alpha.yahoo.com/ are examples of knowledge exchange sites where audiences can discuss their experiences and develop discourses around museum content completely separate to those which are developed by the museum. Such conversations provide valuable insights in to the 'meanings' which audiences have constructed from their museum experiences. Increasingly, museums professionals such as curators and educators should be aware of these conversations, particularly of whether the:

- audience is seeking to speak with them,

- museum is interested in engaging in conversations

- museum is ready to listen to the issues which are being raised.

\section{Experience}

The social role of museums has changed dramatically in the last decade, and the notion of sharing experiences and stories is increasingly of concern in online environments. Enabling audiences to share and discuss their common experiences provides an important insight into collection records. The workshop focused on providing frameworks for content creation and cultural communication. The premise was that content creation could provide novel online experiences which encourage debate and networking. Importantly, the museum would affirm its role in this knowledge exchange by providing tools, infrastructure and content through which audiences could engage with collections and create new forms.

\section{Environment}

Social media provide an innovative way in which museums can public acknowledge their audiences' experiences and voices. By enabling information sharing, response to issues and the creation of new knowledge and content, some museum professionals could be concerned that the authority of the museum is compromised. Yet the existence of social media in itself does not necessarily extend to audience participation. Our research has indicated that organisational support for greater audience participation can go some way to breaking down internal information and knowledge silos thus enhancing communication between staff. The workshops developed the notion that museums could play an active role in cultural participation while extending their authority by encouraging knowledge sharing and community voice; developing educational programs which include engagement with collections online and by acknowledging the value which 'non-expert' audiences bring to museum collections.

\section{Evaluation}

With the ability to voice opinions comes the opportunity for the museum to acknowledge the vast informal knowledge held by its audiences while extending its position within the community as expert knowledge provider. Yet this type of participation has proven difficult to measure. As publicly funded organizations, museums are tasked with developed units of measure to demonstrate the value and benefits of their programs. Throughout the workshop development, evaluation of socialmedia experiences 
came to be structured around four key elements: internal self management, that is, the rules of engagement established within the organization; ambient presence of the organization on other site such as Technorati and Flickr; strategic conversion of virtual to physical visitors and the number of citations which particular programs achieved. Over the life of the project, this section of the research has proven the most dynamic. While the technologies have developed into quite sophisticated devices in a relatively short time, the tools by which we evaluate engagement are still in their infancy. In our next funded research project, 'Engaging with Social Media in Museums'

(see http://museum30.ning.com/group/engagingwithsocialmediainmuseums) we will be investigating this in more detail.

\section{Policy Impacts}

In a Demos report, Publicly-funded Culture and the Creative Industries [19], Holden suggests that cultural organisations are important to the innovation and enterprise agendas of the creative industries due to their ability to: act as cultural brokers; act as a legitimate source of emerging creative talent; provide a memory resource; utilize their education departments for the distribution of culture to a wide audience and provide spaces for networking. Yet Holden admits that little work has been done to probe how the relationships between publicly-funded culture and the creative industries can function.

This report was significant for our research because it described the lack of connection between theory, policy and practice in the cultural organization sector. It also went some way to addressing the issues which we had been investigating in relation to the rise of user-generated content and participatory design strategies within cultural institutions. Holden proposed a typology of interactions between the creative industries and publicly-funded culture suggesting that it:

- could help to theorise the creative industries;

- developed human capital skills that are applicable across a wider field, into the creative industries and beyond;

- provided spaces and places for the development of creative industries' networks and serendipitous exchanges;

- had outputs that could become the stimulus, and sometimes the inputs, for the creativity of others.

These findings suggested that cultural institutions could be considered a driver of the skills, knowledge and practices which can direct creative industries policy into audiencedriven engagement and can lead innovation and forms of enterprise formation. At the same time, Cunningham et al[20] proposed that "the quality of linkages and the lack of clear public policy signals and frameworks, together with a number of other critical issues mark the innovation system as embryonic at best." They suggested that public policy would need to address significant shifts in public institutions if it was to capture the innovation potential and create a more fluid mix of coordinated program initiatives.

In February 2008, The Cultural Ministers Council of Australia and New Zealand released The Building a Creative Innovation Economy report [19]which documented the 
growing contribution of the creative sector to the innovation economy and identified opportunities and key shared priorities for the creative sector in the digital environment.

The report defined cultural organizations as part of the creative industries and stressed that 'audiences are creating demands for greater online interactivity with the creative sector, giving rise to the increased significance of an online presence through which organizational, commercial and personal goals can be realised'. The report defined a broad range of opportunities in the creative innovation model. Those of particular reference to our research were the need to: improve access to culture in the digital environment; increase production of creative digital content through community participation; commercialize the creative innovation economy and strengthen creative sector partnerships.

Increasingly, our research has addressed the need to engage with cultural policy to extend the theoretical underpinnings and practical applications which have driven our agenda. Our approach, from the initial stages of defining and developing digital literacy programs to exploring new avenues for audience participation through social media have been driven by the quest to create fluid, dynamic, audience-driven communication which acknowledges the legitimacy and value of digital content creation in the innovation debate.

\section{CONCLUSIONS}

The key understandings which arose from this research are:

- To achieve representative curatorial practices, new design methods for cultural interactive experience are required.

- Achieving cultural engagement with communities and collections relies on new models of information literacy

- Establishing and maintaining cultural e-communities requires structured and sustainable strategies

- Digital Cultural Communication can achieve these understandings by focusing on cultural participation and engagement, sustainable practices, digital literacy programs and design methods for creating cultural interactive experiences.

This project has brought together arguments from media/ cultural studies, education, design and human computer interaction to describe the similar concerns each discipline has with "literacy" in the information age. The project has sought to define how audiences engage with cultural organizations online and has sought to enhance learning environments with immersive cultural materials enabled by social media. It has produced training materials for both 'new literacy' and 'new audiences'. To a much lesser extent, the project has sought to situate these discussions within evolving cultural and creative policy frameworks. In the future, this research could provide the basis for strategic cultural communications programs and innovations within the sector.

Ten key words and definitions

Digital Cultural Communication 
A new field of research and design which seeks to build a co-creative relationship between the cultural institution and the community by using new media to produce audience-focused cultural interactive experiences

\section{Digital Literacy}

The skills required to use digital technologies to engage in both cultural consumption and production

\section{Cultural Participation}

The creation of cultural experiences which retain their critical and instructive content while focusing on the experience of cultural consumption.

\section{Cultural Participant}

The cultural participant has the "digital literacy" which enables participation in Digital Cultural Communication through interaction with - and even creation of - digital cultural content. Such skills might be the result of specific community-based training, education or general cultural absorption via internet browsing.

\section{Cultural interactive experiences}

The capture and analysis of disparate audience needs and the creation of new digital cultural content which includes user-led innovations.

\section{Participatory Media}

Participatory media enable widespread active participation in production of culture, power, community, and wealth. They include (but aren't limited to) blogs, wikis, RSS, tagging and social bookmarking, music-photo-video sharing, mashups, podcasts, and videoblogs.

\section{Participatory Design}

An evolution of user-centred design which considers the audience as an equal collaborator within the design process.

\section{Representative Curatorial Practice}

Processes through which curators frame participation and interaction with digital cultural content by actively seeking narratives and experiences which include audiences in their conception and distribution.

\section{Multi-platform Communication Design}

A bespoke design system created to enable community members to learn the skills necessary to create digital content. The methodology includes a "purpose-built" training program which could deliver the skills necessary for organizations to facilitate the creation of new content.

Cultural Co-creation 
EVA 2008 London Conference 22-24 July

Angelina Russo and Jerry Watkins

Processes through which audiences and institutions collaborate to create new and engaging interactive experiences. Successful cultural co-creation programs are structured to consider capture, display, distribution and promotion of new content.

Project publications

Russo, A. and Watkins, J.: Digital Cultural Communication: Audience and

Remediation. In: Cameron, F. and Kenderdine, S. (eds.): Theorizing Digital Cultural

Heritage. Cambridge, Mass., MIT Press (2006), ISBN 978-0-262-03353-4 pp. 149-164.

Watkins, J., and Russo, A.: Beyond Individual Expression: Creative Tools, Systems and Teams. In: Hartley, J. and McWilliam, K. (eds.): Story Circle: Digital Storytelling around the World. Malden, MA: Wiley-Blackwell (forthcoming 2008)

Russo, A., and Watkins, J.: Media Museum: towards an ontology for social networking and digital cultural content creation in Griffin, D., Anderson, M., and Paroissien, L. (eds) Museums in Australia 1970-2007. National Museum of Australia. Canberra (forthcoming 2008)

Russo, A., Watkins, J., Kelly, L., Chan, S. Participatory Communication with Social Media. (2008) Curator, The Museum Journal Volume 51, Issue 1, pp.21-32.

Russo, A., Watkins, J., Kelly, L., Chan, S. 'How will social media affect museum communication?' Nordisk Museologi Issue 1(2007) ISSN 1103-8152 pp. 19-29

Russo, A. and Watkins, J. 2005, Digital Cultural Communication: enabling new media and co-creation in Asia. International Journal of Education and Development using Information and Communication Technology (IJEDICT) Volume 1, Issue 4 (2005) http://ijedict.dec.uwi.edu/viewissue.php?id=6

Russo, A and Watkins, J. 2006, 'Establishing and Maintaining Cultural e-Communities' in WSEAS Transactions on Advances in Engineering Education. Issue 1, Volume 3, January 2006, ISSN 1790-1979. pp. 27-33.

Watkins, J. and Russo, A. (2007): Participatory Design and Co-creativity in Cultural Institutions. Museums Australia Conference, Canberra, May 2007.

http://www.museumsaustralia.org.au/

Watkins, J. and Russo, A. (2007): Cultural Institutions, Co-creativity and Communities of Interest. In: Schuler, D. (ed.): Online Communities and Social Computing, HCII 2007, LNCS 4564, pp. 212-221

Russo, A., Watkins, J., Kelly, L., Chan. S. (2006): How will social media affect museum communication? Nordic Digital Excellence in Museums (NODEM 06) Oslo, Norway December 2006. http://www.tii.se/v4m/nodem/nw 06/papers/papers.htm

Watkins, J. and Russo, A. 2005, 'Developing communities and collections with new media and information literacy' in Digital Libraries: Implementing Strategies and 
EVA 2008 London Conference 22-24 July

Angelina Russo and Jerry Watkins

Sharing Experiences, eds. Fox, E. et al, Springer, pp. 390-394, ISBN 354030850

Russo, A. and Watkins, Jerry (2005) Post-museum experiences: structured methods for audience engagement. In Thwaites, H, Eds. Proceedings Eleventh International Conference on Virtual Systems and Multimedia, pages pp. 173-182, Brussels

Watkins, J and Russo, A. 2005, 'New media design for cultural institutions' in Designing for User eXperience (DUX) 2005 Proceedings, San Francisco, California. ISBN: 1-59593-250-X

Russo, A. and Watkins, J. 2005, 'Digital Cultural Communication: tools and methods for community co-creation' in Proceedings of International Conference on Engaging Communities, Brisbane, Australia, Queensland Department of Main Roads, online, ISBN 1920719032

Watkins, J. and Russo, A. 2005, 'Digital Cultural Communication: designing cocreative new media environments' in Creativity \& Cognition, Proceedings 2005, ed. L.

Candy, ACM SIGCHI, pp. 144-149

Watkins, J. and Russo, A. 2005, 'Extending Site-Specific Audience Experience via Multi-Platform Communication Design, in Internet and Multimedia Systems and Applications (IMSA), Proceedings, ed. M.H. Hamza Calgary, ACTA Press.

Russo, A. and Watkins, J. 2004, 'Creative new media design: achieving representative curatorial practice using a Cultural Interactive Experience Design method' in E.

Edmonds and R. Gibson (eds.) (2004) Interaction: Systems, Practice and Theory, ACM SIGCHI, pp.573- 597

\section{ACKNOWLEDGEMENTS}

This project has funded by the Australian Research Council through the Centre for Creative Industries and Innovation. The Authors wish to thank the industry partners: Australian Museum, Powerhouse Museum, National Museum of Australia, State Library of Queensland, Queensland Museum and the Australian Centre for the Moving Image for their collaboration.

\section{References}

[1] MILLER, S: A Theory of Shopping. 1998. Cambridge: Polity.

[2] ABERCROMBIE, N \& Longhurst B: Audiences: A Sociological Theory of Performance and Imagination. 1998. London: Sage.

[3] JENKINS, H: Games, the New Lively Art. In J Goldstein and J Raessens (eds) Handbook of Computer Game Studies. 2003. Cambridge, MA: MIT Press.

[4] HARTLEY, J: Uses of Television. 1999. London \& New York: Routledge.

[5] LESSIG, L: The Future of Ideas: The Fate of the Commons in a Connected World. 2001. New York: Random House.

[6] LEADBEATER, C \& P Miller : The Pro-Am Revolution. 2004. London. Demos. 
EVA 2008 London Conference 22-24 July

Angelina Russo and Jerry Watkins

First accessed 12/11/04 http://www.demos.co.uk/publications/proameconomy

[7] NIXON, H: Textual diversity: who needs it?. 2003. Proceedings of

International Federation for the Teaching of English Conference, Melbourne, Australia.

[8] LEU, D., Kinzer, C., Coiro, J., Cammack, D: Toward a Theory of New

Literacies Emerging From the Internet and Other Information and

CommunicationTechnologies,

www.readingonline.org/newliteracies/lit_index.asp?HREF=/newliteracies/leu.

First accessed 6th January 2005.

[9] LIVINGSTONE, S: The Changing Nature and Uses of Media Literacy in R.

Gill, A. Pratt, et al [eds.] MEDIA@LSE Electronic Working Papers,

MEDIA@LSE, 2002. London School of Economics and Political Science,

London.

[10] SCHULER, D. Community networks: Building a new participatory medium, Association for Computing Machinery. 1994. Communications of the ACM, 37 [1], 38.

[11] CAPTURE WALES, www.bbc.co.uk/capturewales first accessed 28th November 2004.

[12] WATKINS, J. and Russo, A: Extending Site-Specific Audience Experience via Multi-Platform Communication Design, in Internet and Multimedia Systems and Applications (IMSA), 2005. Proceedings, ed. M.H. Hamza Calgary, ACTA Press.

[13] LI, C: Social Technographics. Mapping Participation In Activities Forms The Foundation Of A Social Strategy. 2007. Cambridge, MA: Forrester Research.

[14] AUSTRALIAN MUSEUM. Visitor Profile 2005-2007. 2007. Sydney:

Australian Museum.

[15] RUSSO, A., Watkins, J., Kelly, L., Chan, S: Participatory Communication with Social Media. 2008. Curator, The Museum Journal Volume 51, Issue 1, pp.2132.

[16] AUSTRALIAN MUSEUMS ONLINE (AMOL), 11 Feb 2007. http://www.amol.org.au

[17] AUSTRALIAN MUSEUM AUDIENCE RESEARCH CENTRE, 10 Feb 2007. http://www.amonline.net.au/amarc/index.htm

[18] LIVINGSTONE, ibid

[19] HOLDEN, J: Publicly funded Culture and the Creative Industries. http://www.demos.co.uk/publications/publiclyfundedcultureandthecreativeindus ries

[20] CUNNINGHAM, S. Cutler, T. Hearn, G. Ryan, M. and Keane, M. (2004) An Innovation Agenda for the Creative Industries: Where is the R\&D? Media International Australia; Incorporating Culture \& Policy (112): pp. 174-185. First accessed 15/10/07 http://eprints.qut.edu.au/archive/00002465/01/2465.pdf

[21] CULTURAL MINISTER'S REPORT. First accessed 1/03/08

http://www.cmc.gov.au/_data/assets/pdf_file/7817/Building_a_Creative_Innov ation_Economy.pdf 